\title{
Terrain characteristics and Tai toponyms: a GIS analysis of Muang, Chiang and Viang
}

\author{
Wei Luo $\cdot$ John F. Hartmann $\cdot$ Fahui Wang
}

(C) Springer Science+Business Media B.V. 2009

\begin{abstract}
Tai is a family of related languages and dialects, a subgroup of the Tai-Kadai languages, spoken by more than 85 million speakers in southern China and Southeast Asia. This paper uses GIS to map the spatial distribution of Tai toponyms (Muang, Chiang and Viang) and analyzes their relationship with terrain characteristics. In Tai, Muang means flat "basin", Chiang means "town", and Viang provides defense for a Chiang. These Tai toponyms are found at places with a significantly higher compound topographic index (or wetness index) than others. Watershed basins with more Muang toponyms are characterized by lower elevation, gentler slope, near zero concavity. All of these are consistent with physical conditions favorable for wet rice agriculture, culture, and commerce. The transnational spatial distribution of these toponyms and associated terrain characteristics reveal a significant regional pattern that reflects not only the geomorphology of the places where Tai expanded and settled, but also a common history and culture of naming places influenced by their wet rice agriculture and associated cultural practices and commerce.
\end{abstract}

W. Luo $(\bowtie)$. J. F. Hartmann

Northern Illinois University, DeKalb, IL, USA

e-mail:wluo@niu.edu

F. Wang

Louisiana State University, Baton Rouge, LA, USA
Keywords Tai toponyms - Terrain characteristics . GIS - Water resource - Wet rice agriculture

\section{Introduction}

Purposes of the paper

Traditional toponymical studies are qualitative and descriptive in nature and their spatial coverage is often limited to local scale. Despite the advancement of GIS technology and its great impact in various fields over the past two decades, GIS applications in historical-linguistic-cultural studies remain limited, and even fewer have employed advanced spatial analysis methods. Kwan (2004) promotes the notion of "hybrid geography" including using GIS-based spatial analysis methods in historical and cultural geography. Bridging the two helps advance our fundamental understanding of the dynamics underlying social and cultural changes. In addition, many social scientists are aware of the important impacts of the physical environment on human activities, but have rarely been able to examine the interaction between them in an integrated manner. The long tradition of making a distinct division between physical and human geography within the discipline of geography is an example (Rhoads 2004). By examining the different terrain characteristics 
between $T a i^{1}$ toponyms and non-Tai toponyms, this paper attempts to illustrate how the settlement of Tai has been closely related to terrain characteristics and thus demonstrates the benefits of an integrated perspective.

As a first step toward a more thorough analysis of Tai toponyms, we map the spatial distribution of three major high-level Tai place names Muang, Chiang and Viang and examine their relationship with terrain characteristics. Study of these Tai toponyms covering the macro-region of the entire Tai speaking domain will shed light on past Tai settlement and migration patterns and the evolution of place naming practices. The objectives of this paper are three-fold: (1) to demonstrate how GISbased geovisualization techniques enhance the view of geographic patterns of Tai toponyms from the vantage of the transnational spatial distribution of these toponyms in southern China and Southeast Asia; (2) to test the hypothesis that areas with high concentrations of Tai toponyms have unique terrain characteristics particularly amenable for Tai wet rice agriculture; and (3) to demonstrate the value of hybrid geography and benefits of integrating physical and human geography.

Background on toponyms, Tai (the language) and Tai (the people)

Toponyms (place names) often directly reflect spatial patterns of languages, dialects, and ethnicity, and may offer insights into the history, habitat, spatial and environmental perceptions of a certain culture (Jett 1997). Geographers and others have long used toponyms to provide clues as to the historical and cultural heritage of particular places and even large regions (e.g., McDavid 1958; Rickard 1968; Gelling 1988; Kashif 2001), because place names may survive long after a culture has vanished, thereby preserving traces of the past. The naming of places is also an integral aspect of the relationship between place and the politics of identity and power, as toponyms are often used by the authorities to promote their own ideological and political objectives (e.g., Cohen and Kliot 1992; Myers 1996; Horsman 2006;

\footnotetext{
${ }^{1}$ In this paper, we use italicized font Tai to indicate the Tai language and the normal font Tai to represent the people who speak Tai.
}

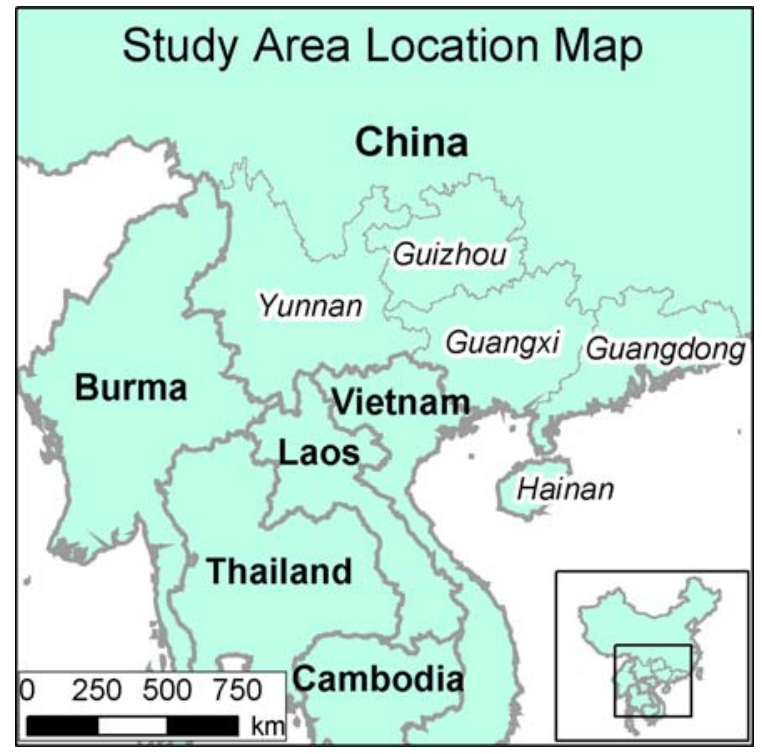

Fig. 1 The study area location map. This also shows the general Tai speaking domain (Note: Guizhou, Guangdong, and Hainan provinces are not included in this exploratory research, but in a future full-scale project)

Hartmann 2007). In addition, toponyms are often related to the physical environment and reflect perception of the residents about the environment they live in (e.g., West 1954; Jiang 1990; Jett 1997). Previous studies have also shown that toponyms illustrate ethnic settlement patterns and help identify discrete periods of population movements (e.g., Kaups 1966; Miller 1969). However, many of these earlier studies are qualitative and descriptive in nature.

Tai is a term used to designate a family of related languages and dialects, a subgroup of the Tai-Kadai languages, spoken by more than 85 million speakers in southern China and Southeast Asia (Diller and Edmondson 2005). ${ }^{2}$ Tai also refers to those who speak Tai; their domain stretches from the island of Hainan, through much of the north of Vietnam and areas of southwestern China (chiefly Guangxi, Guizhou and Yunnan), through Laos and Thailand, across the northern reaches of Burma and finally into Assam in India (Diller and Edmondson 2005) (see Fig. 1).

The Tai were thought to have originated from the ancient Yue peoples, who lived in southeastern and southwestern China south of the Yangtze River

\footnotetext{
2 Thai or Siamese is only one of many Tai languages and refers only to the national language of the modern Thai nation.
} 
before the Xia and Shang dynasties (Luo 1996: 36). The Tai are well known for their wet rice agriculture in irrigated fields (e.g., Kato 1998; Falvey 2000). They began expanding in a southwest fanning pattern around 2,000 years ago into Vietnam, Laos and Thailand in search of the best land on which to grow padi rice (Enfield 2003; Wyatt 1984; Hartmann 1998: 82). In fact, Hartmann (1998) suggests that "being Tai" is a cultural construct centered around the emergence of irrigated rice technology in southern China that came to be dominated and spread by genetically diverse peoples who shared a basic agrarian vocabulary and naming tradition that linguists identify as Tai.

\section{Tai toponyms: Muang, Chiang and Viang}

Historically, the Tai settled in many intermontane basins called Muang (meaning "basin" in proto-Tai), some as small as $10 \mathrm{~km}^{2}$ in area. Muang is still preserved in some remote Tai dialects such as Dehong in western Yunnan, China. In these ecological niches, the Tai controlled irrigation waters flowing from mountain streams and channeled through a highly developed distinctive system of canals and dams called Muang Fai (or ditch-and-dike irrigation system), which enabled them to produce a dependable supply of rice and thus expand from one basin to another far beyond their geographic origins and project their economic and political influence to much of mainland Southeast Asia (Hartmann 1998; Falvey 2000, Chap. 3). As the Tai migrated, they often named the places they settled according to identifiable landscape features, such as Muang for "basin". Many such toponyms stayed even after the Tai moved out of the area. Thus Tai toponyms are often a reflection of the environment. This is especially true for village-level toponyms (Dai 2004). However, the original geomorphological term Muang, a mountain-bounded floodplain that lends itself to centralized governance, has over time become a geopolitical one, namely, "chiefdom, kingdom, polity, or country". Thus we have today's "Muang Thai," Thailand, and "Muang Lao", Laos. $^{3}$

\footnotetext{
${ }^{3}$ Tai/Thai is a tonal language; a change in tone results in a change in meaning. The tones of Muang "basin" and Muang "ditch" are, in modern Thai speech, level tone and rising tone, respectively.
}

As early Tai speech communities migrated and came into contact first with Han Chinese, in a process often referred to as Sinification, and later with the Mon-Khmer peoples who had already been Indianized or undergone Sanskritization, new regional patterns and practices of naming prominent places emerged in place of or in addition to declaring a place to be a Muang. An early candidate for naming was Chiang, roughly meaning "town". This label appears to have been borrowed from or imposed by the (Sino-) Tibeto-Burman speaking rulers of the Nan Chao kingdom of Yunnan for the purpose of establishing a system of prefectures in the eighth and nineth centuries (Barlow 2005; Blackmore 1960). Chiangs often acted as entrepots (trading centers) collecting product from the hinterland for transport and export elsewhere. Places formerly declared to be Chiang are found predominantly, but not exclusively in the northern half of the current Tai speech domain, with notable concentrations along the middle Mekong. Kengtung (Chiang Tung) in the Shan State in Burma, Jing Hong (Chieng Rung) in Yunnan, China, and Chiang Mai in northern Thailand are well known examples of Chiang that served as political and trade centers in many of the Muang. In a sense, the appearance of Chiang probably marked the emergence of urban centers in this region of multiple Muang. Places labeled Viang/Wiang have the same general regional distribution but with lower frequency and permanency. The function of a Viang "citadel, palisade" was principally one of providing defense for a Chiang. In some areas, the meaning and function has evolved to indicate a walled compound for the ruling class of a Chiang.

In summary, a study of toponyms containing Muang, Chiang, and Viang is thus an opening hatch to a panoramic view of linguistic and historical patterns of Tai settlements and the evolution of their practices for naming places that are rich reflections of the environment - and wet rice agriculture production and trade in particular-and their interaction with other cultures. The emergence of a clearly Tai phenomenon of Muang represents the early stage of the Tai as masters of irrigated rice farming; the appearance of Chiang-Viang is a later stage of economic and political development with SinoTibetan roots. 


\section{Study area and data sources}

The area of focus in this study is the Tai-speaking domain covering southwestern China, northern Vietnam, Laos, northern Burma, and Thailand as shown in Fig. 1.

The toponym data are downloaded from "GEOnet Names Server (GNS)" database (http://earth-info. nga.mil/gns/html/index.html), which is the official repository of standard spellings of all foreign place names, sanctioned by the United States Board on Geographic Names. This dataset contains Romanized names for each place, its latitude and longitude, administrative division code, among other things. The data were downloaded by country and merged into one database, which can be easily brought into GIS for mapping and visualization by their geographic coordinates. This dataset is the best source for mapping the overall spatial pattern of the three major high level Tai place names Muang, Chiang and Viang and is sufficient for our purpose. The topographic data come from GTOPO30 (http://edc.usgs.gov/products/ elevation/gtopo30/gtopo30.html), a global digital elevation model (DEM) with a horizontal grid spacing of 30 arc seconds (approximately $1 \mathrm{~km}$ ). This dataset was compiled from several raster and vector sources of topographic information, including digital terrain elevation data and digital chart of the world, by United States Geological Survey (USGS). For this macro-regional study of the general pattern of spatial distribution of Tai toponym and terrain characteristics, the GTOPO30 data is sufficient. The river network data and country boundaries were obtained from the Environment System Research Institute (ESRI), which are necessary for computing distances from places to nearest river and for visualizing the relationship between waterways and Tai toponyms.

\section{GIS analysis and results}

Based on what we described in the Introduction and the original meaning of Muang being a basin, we hypothesize that areas with high concentration of toponyms starting with head noun Muang would have some terrain characteristics that are different from those with low or no Muang toponyms. $^{4} \mathrm{We}$ will first examine the general spatial distributions of the Muang toponyms and then explore their relationships with terrain characteristics. We will also examine the spatial distribution of related toponyms starting with Chiang and Viang and their relationship with river networks. All GIS analyses were conducted in ESRI's ArcGIS software.

Spatial distribution of Tai toponyms and geovisualization

Using the toponym data from "GEOnet Names Server (GNS)", we selected all place names starting with Tai head nouns, excluding the administrative region type features, and mapped their spatial distributions. Figure 2 shows the spatial distribution of Muang (and its variations Muang, Mong, Muong, Meng, Meung, Mueng). There are 1,221 such points (shown as red) out of a total 188,000 points in the study area (non-Muang points not shown for clarity). Muang place names are quite widespread, but mostly distributed in Laos, Thailand, eastern Burma, and northern Vietnam.

Figure 3 shows the spatial distribution of place names starting with Chiang (and its variations Chieng, Chiang, Xiang, Siang, Ching, Jing, Keng, Siang, Ching, Keng, Ceng)-212 out of 188,000 points. They form three clusters near four major rivers: the Mekong in the border area of Thailand and Laos; the Song Ma in Northern Viet Nam; the Nam $\mathrm{Ou}$ in Northern Laos near China; and the Banghiang in Southern Laos. This pattern underscores the role that rivers played as lines of communication (spreading names and facilitating trade). Chiang served as small ports along waterways that brought in trade from the hinterland. Hoang (2004) has brought to light the obscured record of a second region where places bore the name Chiang, principally in the Tai region of northwestern Vietnam, but even including Hanoi itself, which at one time was called Chiang Lôi (Co Loa). The cluster in northern Vietnam confirms the findings of Hoang (2004). Taking a regional perspective, one can see a pattern of Chiang settlements extending from Hanoi (Chiang Lôi) all the way

\footnotetext{
${ }^{4}$ In general, Tai toponyms follow the pattern of Head Noun (or general name), plus one or more modifiers (or special name) (Dai 2004).
} 
Fig. 2 Spatial distribution of Muang (and its variation) shown as big red dots. NonMuang place name points are not shown for clarity. The small gray dots (with actual spacing of $\sim 12 \mathrm{~km}$ but shown at twice the spacing for clarity) are the sampling points for calculating Muang ratio as described in "Terrain Characteristics of Watershed Basins with High Muang Ratios" (Color figure online)

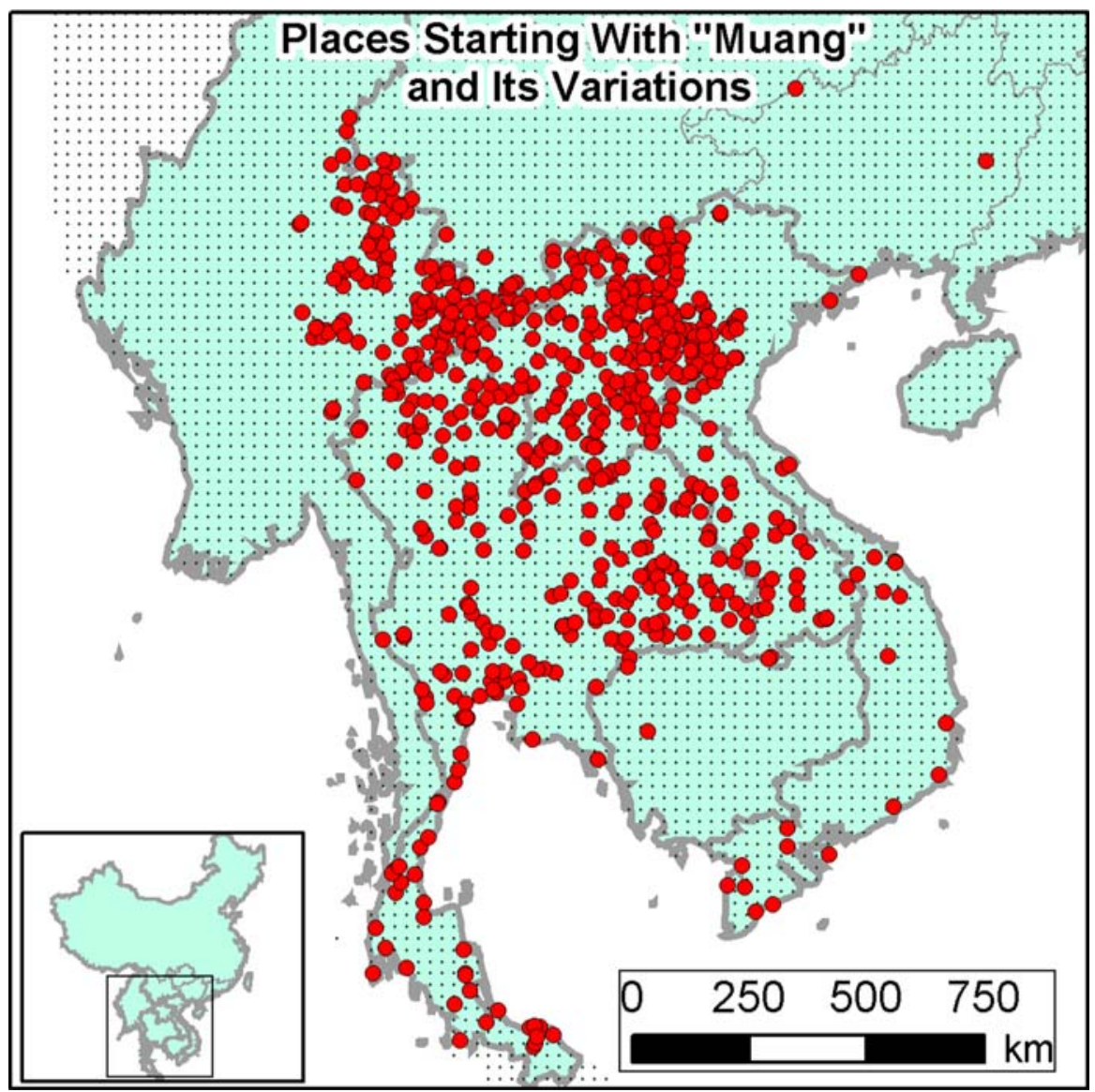

back to the Tai region in Yunnan, China. At this point in our study, we are beginning to speculate that the long chain of Chiang in the region was the product of earlier expansion of the rulers of the kingdom of Nan Chao in Yunnan. As their power waned, centers that were once named Chiang were renamed to reflect the language of the new rulers, the Vietnamese or the Lao, for example.

Figure 4 shows the spatial distribution of place names starting with Viang (and its variations Wieng, Wiang, Vieng, Weng, Veng)—only 27 such points exist, a much lower frequency than Muang and Chiang, and they are mostly concentrated in border areas between Burma, Laos, Thailand and China, where the Salween, Ping, and Mekong rivers run through. Comparing with Muang and Chiang, Viang place names are a "northern" (Thailand, Burma, Laos) phenomenon. Viangs are few in number because many were only transitory outposts set up as part of a rudimentary defense system of a particular Chiang and not every Chiang had a Viang in its periphery. Viangs could be landbased, not located on rivers, because their function was to protect/warn the Chiang (on water). Over time, most of transitory outposts have probably disappeared from the pages of history and modern maps.

In summary, the spatial distributions of Chiang and Viang are within the general spatial domain of Muang (see Figs. 2, 3, 4), confirming their relationship with Muang and the renaming practices documented in the literature (Barlow 2005; Blackmore 1960). The above three Tai place names reveal a significant regional pattern that reflects not only the geomorphology of the places where Tai expanded and settled, but also a common history and culture of naming those places at a macro-regional, transnational scale.

To better visualize and further analyze the spatial patterns, we used a kernel density estimation technique (e.g., Luo and Wang 2003; Wang 2006: 36) to 
Fig. 3 Spatial distribution of Chiang (and its variation) shown as big red dots. NonChiang place name points are not shown for clarity. Also shown are rivers as blue lines (Color figure online)

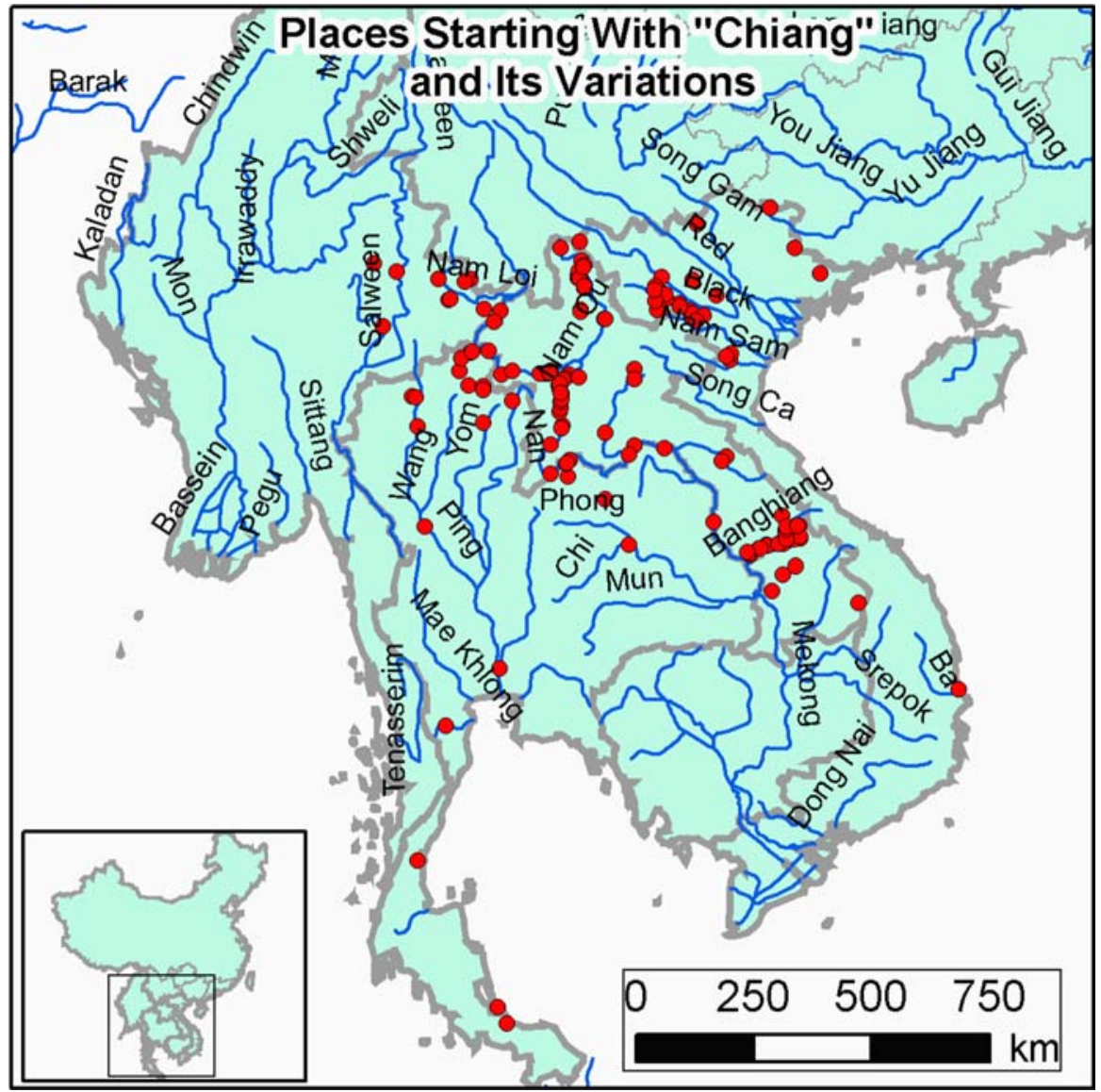

show the relative concentration of Tai (e.g., Muang) toponyms at various locations. The method draws a circle around a sampling point to define a filtering window and uses the ratio of Tai place names among all places within the window to represent the concentration of Tai toponyms at that point. By doing so, nominal data (Muang vs. non-Muang) are converted to numerical data (Muang ratio) at various places, and thus detailed variations of relative concentration of Muang toponyms are obtained, and this facilitates further analysis.

The kernel density estimation process works as follows: (1) first lay a grid of sampling points over the study area (see small gray dots in Fig. 2); (2) draw a circle of a certain radius at a sampling point; (3) count the number of toponym points that are Tai and the total number of toponym points falling inside that circle; (4) compute the ratio of Tai toponyms among all toponyms; (5) assign the ratio to the sampling point under consideration; (6) repeat steps (2) through (5) until all the sampling points are calculated. We experimented with various radii, and found that a final radius of $50 \mathrm{~km}$ generated a reasonable degree of smoothing (regional trends) while preserving needed local details.

The result from the kernel estimation is still discrete point data. To make it easy for further analysis, we converted the point data to a continuous raster surface by setting the raster cell size the same as the spacing of the sampling points $(\sim 12 \mathrm{~km})$. The result (Fig. 5) shows a better overview of general trends across the study area. Comparing with Fig. 2, this continuous surface is more intuitive and clearly demonstrates areas of high concentration of Muang toponyms in southwestern Yunnan Province of China (mostly in Xishuangbanna prefecture), eastern Burma, northern Thailand and Laos. The result is used for the quantitative analysis that follows. 
Fig. 4 Spatial distribution of Viang (and its variation) shown as big red dots. NonViang place name points are not shown for clarity. Also shown are rivers as blue lines (Color figure online)

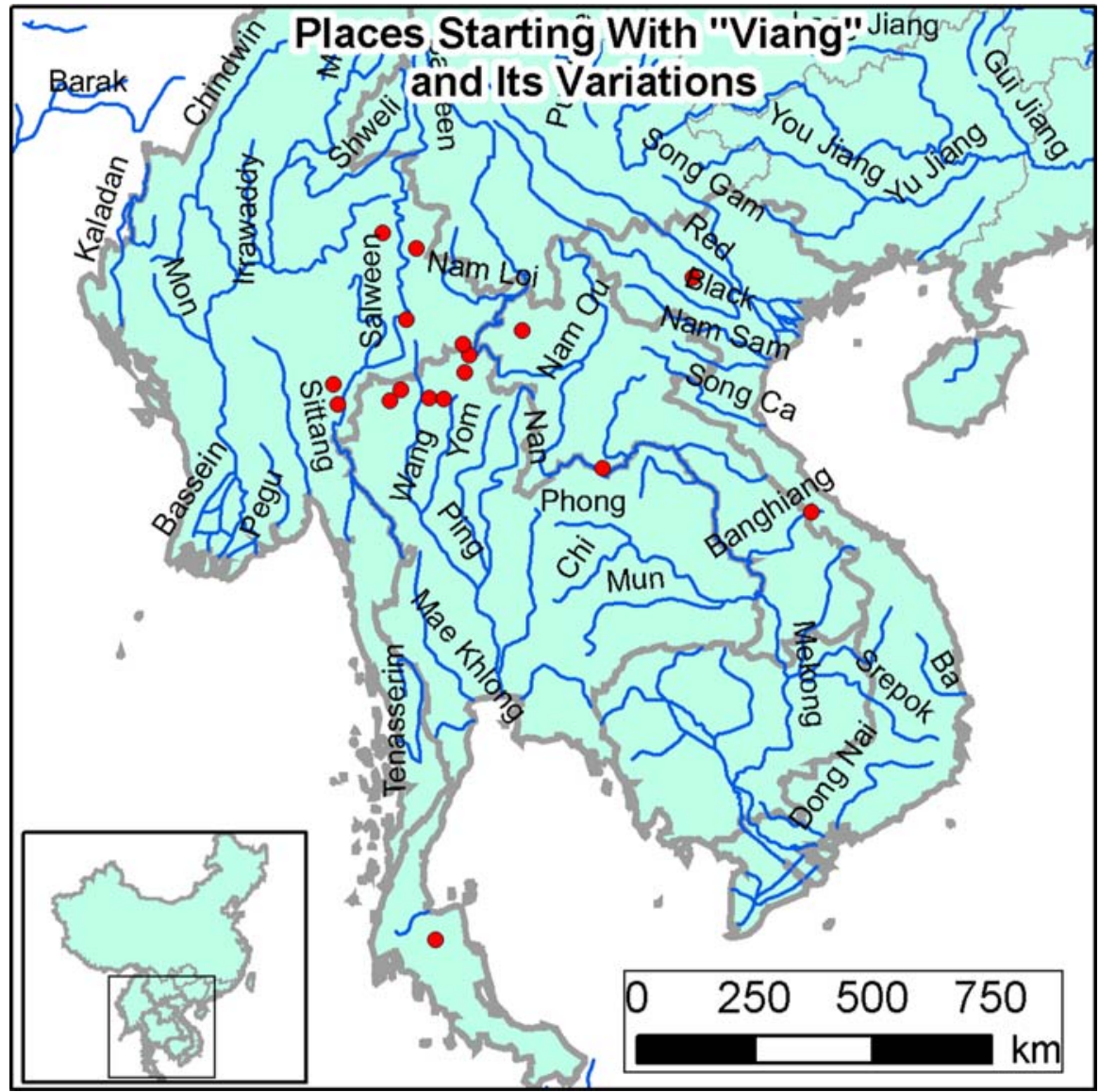

Terrain characteristics of watershed basins with high Muang ratios

In order to examine the terrain characteristics of places starting with the head noun Muang, we delineated watershed basins from the Digital Elevation Model (DEM) and extracted the following terrain parameters for each basin: elevation, slope, Bolstad index. These parameters are chosen because they reflect, from different angles, the suitability of a land surface for cultivating wet rice. For example, elevation is the height of a given point above sea level and largely controls temperature, which determines suitability for wet rice. Slope is the angle between the local topographic tangential surface and the local horizon. Wet rice agriculture requires large areas of flat land or low slope angle areas. The slope is calculated by fitting a plane to the elevation values of a $3 \times 3$ window around the processing or center cell and finding out the angle between that plane and the horizontal plane. The Bolstad index is a measure of concavity/convexity of the topographic surface (Bolstad et al. 1998), thus another index for quantifying the flatness of land surface. It is calculated based on a $3 \times 3$ moving window over the topographic surface, using the center cell's elevation value minus the mean of the nine cells. A positive Bolstad index value indicates the center cell is higher than its surroundings (convex), and a negative value indicates the center cell is lower than its surroundings (concave). Zero value means a flat surface.

Figure 6 shows the watershed boundaries derived from topographic DEM data. We compute the mean Muang ratio for each basin and the means of the above terrain parameters for each basin. Red color highlights those basins with high mean Muang ratios. A high Muang ratio is defined as two standard deviations higher than the mean of all basin means. We then test the statistical difference of these parameters between the high Muang ratio basins 
Fig. 5 Interpolated surface of Muang ratio (floating catchment radius $=50 \mathrm{~km}$ )

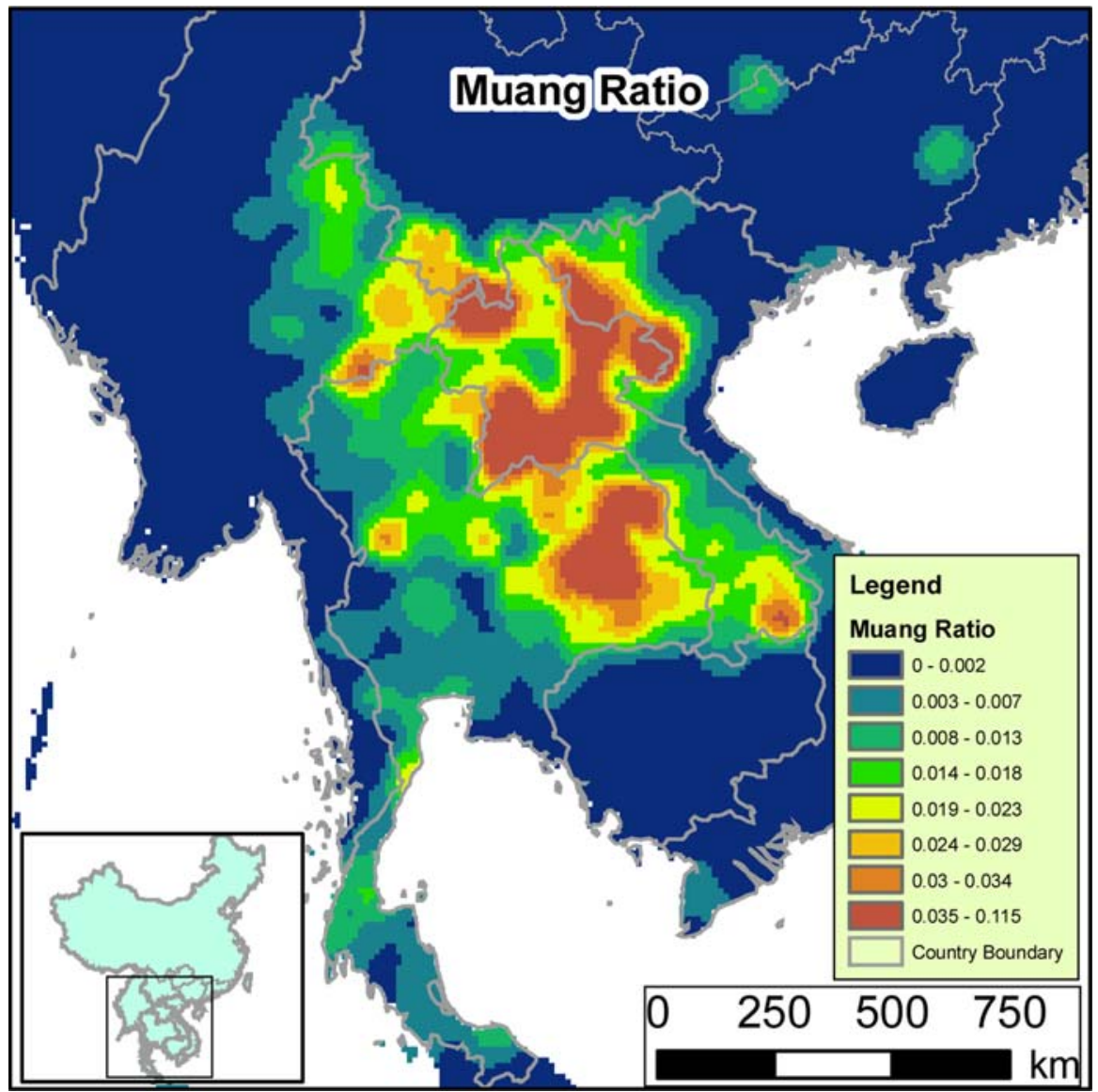

and the rest of the basins. The null hypothesis $\left(H_{0}\right)$ is that there is no difference for the parameter means between the group with a low Muang ratio $\left(\mu_{\mathrm{L}}\right)$ and the group with a high Muang ratio $\left(\mu_{\mathrm{H}}\right): H_{0}: \mu_{\mathrm{L}}=\mu_{\mathrm{H}}$. The alternative hypothesis $\left(H_{1}\right)$ is that there is difference between the two groups $\left(H_{0}: \mu_{\mathrm{L}} \neq \mu_{\mathrm{H}}\right)$. The result indicates that the differences are statistically significant at the $95 \%$ confidence level, and we reject $H_{0}$ in favor of $H_{1}$ (see Table 1). That is to say, basins with high Muang ratios are characterized by lower elevation, smaller slope, closer to 0 Bolstad index (closer to flat surface). All of these are consistent with physical conditions favorable for wet rice agriculture. The implication is that Tai people tend to settle in places that are favorable for wet rice agriculture and name those places in Tai.

CTI between Tai toponyms and others

The compound topographic index (CTI), also commonly referred to as the wetness index (Beven and
Kirkby 1979; Moore et al. 1991), is a function of the upstream contributing area (flow accumulation) and the slope of the landscape. In the formula,

$\mathrm{CTI}=\ln [A / \tan (\beta)]$

$A$ is the upslope contributing area to the point under consideration per unit contour length (often represented as the number of upstream cells that flow into current point multiplied by cell size, see Wolock and McCabe 1995), and $\beta$ is the slope angle of the current point. This parameter describes the effect of topography on the location and size of areas of water accumulation in soils, i.e., the likelihood that a given point will be saturated with water. Places with a low slope (small $\beta$ ) and a large contributing area (large $A$ ) have high values of CTI. These are usually places in the landscape that are flat and near the downstream end of a drainage basin and thus ideal for wet rice agriculture. The difference between this parameter and the other three parameters (elevation, slope, Bolstad 
Fig. 6 Watershed basins with high Muang ratios (red) (Color figure online)

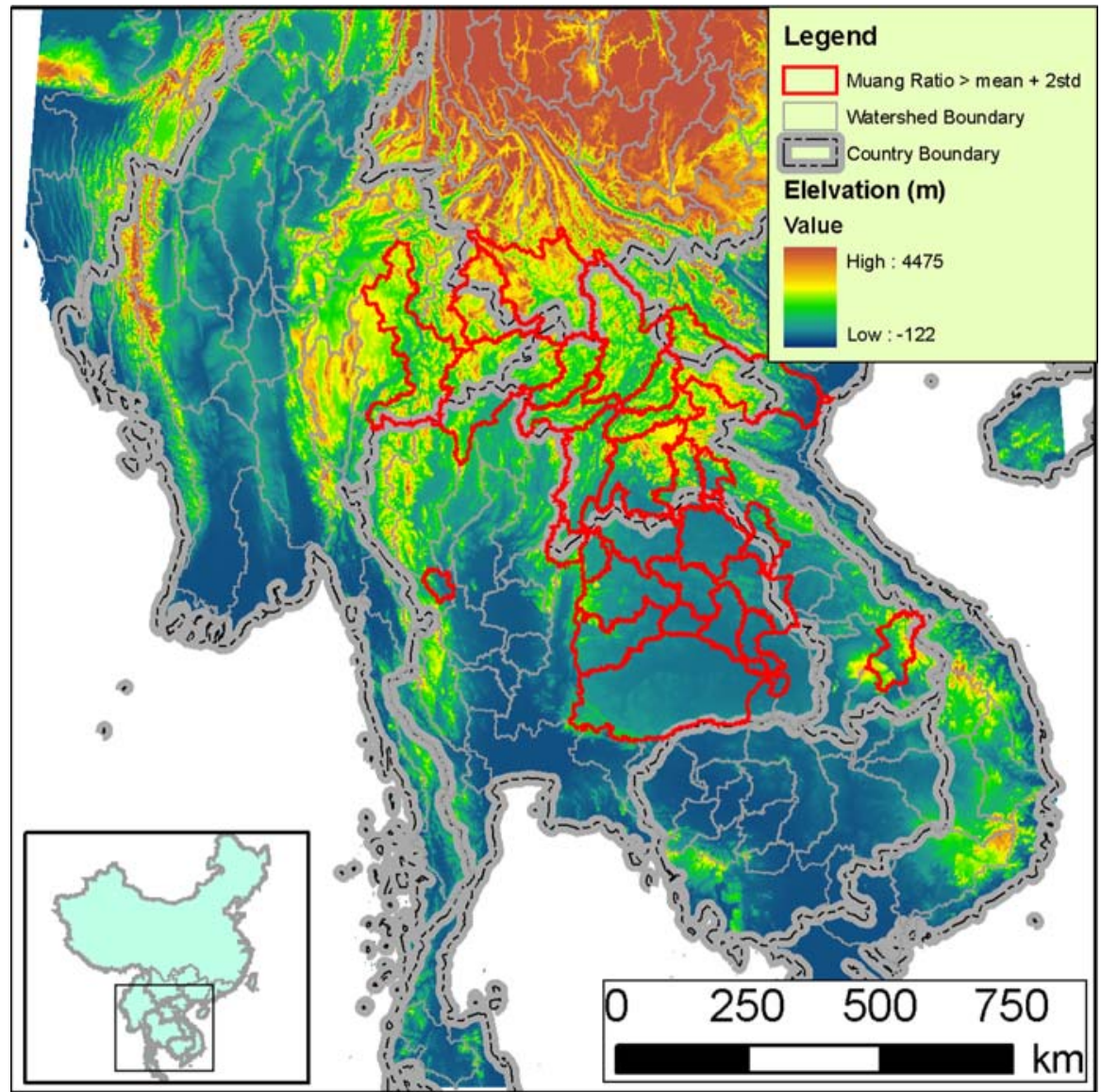

Table 1 Statistical $t$-test of terrain parameters between basins with high and low Muang ratio

\begin{tabular}{|c|c|c|c|c|c|c|}
\hline \multirow[t]{2}{*}{ Terrain parameters } & \multicolumn{2}{|c|}{ Low Muang ratio $(n=32)$} & \multicolumn{2}{|c|}{ High Muang ratio $(n=269)$} & \multirow[t]{2}{*}{$t$} & \multirow[t]{2}{*}{$p>|t|$} \\
\hline & Mean & SD & Mean & SD & & \\
\hline Elevation & 806.76 & 938.44 & 537.44 & 331.92 & 3.2 & 0.002 \\
\hline Slope & 3.9 & 2.91 & 3.09 & 2.06 & 1.97 & 0.055 \\
\hline Bolstad index & -0.24 & 0.21 & -0.17 & 0.13 & -2.58 & 0.013 \\
\hline
\end{tabular}

index) is that the other three are based on a local cell or a $3 \times 3$ local neighborhood whereas CTI considers contribution from upstream cells beyond the local neighborhood. CTI may be considered as a comprehensive index that better captures the environment suitable for wet rice agriculture.

Since this parameter already considers contribution from upstream cells in a watershed, it is not averaged over the whole watershed. Here the statistical difference of CTI values at all individual toponym locations between Tai toponyms (including
Muang, Chiang, and Viang) and others (all the rest of toponyms) is tested. The null hypothesis $\left(H_{0}\right)$ is that there is no difference for CTI values at locations with Tai toponyms $\left(\mu_{T a i}\right)$ and others $\left(\mu_{\text {others }}\right): H_{0}$ : $\mu_{\text {Tai }}=\mu_{\text {others. }}$. The alternative hypothesis $\left(H_{1}\right)$ is that the CTI values at locations with Tai toponyms will be higher than those at other locations $\left(H_{1}: \mu_{T a i}>\mu_{\text {others }}\right)$. The result shows that the CTI values at locations with Tai toponyms (including Muang, Chiang, and Viang) are significantly higher than other locations (see Table 2). 
Table 2 Statistical $t$-test of CTI between Tai and non-Tai points

\begin{tabular}{|c|c|c|c|c|c|c|}
\hline \multirow[t]{2}{*}{ Terrain parameters } & \multicolumn{2}{|c|}{ Tai locations $(n=1,460)$} & \multicolumn{2}{|c|}{ Non-Tai locations $(n=186,540)$} & \multirow[t]{2}{*}{$t$} & \multirow[t]{2}{*}{$p>|t|$} \\
\hline & Mean & SD & Mean & SD & & \\
\hline CTI & 13.66 & 2.83 & 13.16 & 2.75 & 6.98 & $<.0001$ \\
\hline
\end{tabular}

Table 3 Distance to nearest river $(\mathrm{km})$

\begin{tabular}{lll}
\hline & Chiang & Viang \\
\hline$N$ & 212 & 27 \\
Mean & 7.100 & 8.782 \\
Standard deviation & 7.837 & 9.449 \\
\hline
\end{tabular}

Nearest distance to rivers

Based on the discussion in the "Introduction", Chiang and Viang are places named for trade centers and defense outposts. The spatial distribution of these locations (Figs. 3, 4) displays a clustering pattern near rivers. Based on the distance of each Tai point to the nearest river, we compare the differences in their average values between Chiang and Viang points. The statistics are shown in Table 3. The mean distance to nearest river for Chiang points is on average $\sim 1.7 \mathrm{~km}$ shorter than that for Viang points, although statistical $t$-test shows that the difference is not statistically significant $(t=1.02$ and $p=0.3064)$. This observation is still consistent with our current understanding of these Tai place names described earlier. As Chiangs often acted as trading centers and rivers were the major means of transportation in early days, the Chiang's shorter distance to rivers can be expected. Since the function of a Viang/Wiang "citadel, palisade" was principally one of providing defense for a Chiang, they were often village-sized, land-based defense outposts. Not every Chiang was defended by a Viang. In some cases, a Chiang was protected in two directions by twin Viangs, "north/ up-river" and "south/down-river," and, once a Chiang declined in importance, the Viang did also and may have even disappeared from the map and the pages of history. This helps to explain why there were few enduring Viang, such as today's Viangchan/Vientiane in Laos.

\section{Discussion}

The Tai place names we selected from the "GEOnet Names Server (GNS)" database were based on the Romanized form of the head nouns. Although we tried to account for the common variations, it is possible some Tai place names were missed and some that were selected may not be true Tai place names. For example, some Chinese place names may spell the same in Romanized form as a Tai place name, but their original Chinese character may be totally different. In addition, as described in the "Introduction", the meaning of the term Muang has changed over time from a geomorphological one (basin) to a geopolitical or administrative one (chiefdom, kingdom, polity, or country). Many places named Muang are no longer necessarily anchored to any geomorphological feature. Although we tried to exclude the "administrative region type features" based on the "feature classification" field of the database (there are 158 such points, mostly located in Laos), more detailed analysis based on carefully reading of the gazetteer in the original languages will be necessary to confirm their true origin and to differentiate the geomorphological ones from the geopolitical/administrative ones. Despite these uncertainties, we have demonstrated that the GIS approach in general and the spatial smoothing method in particular can help bring out the general trend of toponym distribution at a macro-regional and transnational scale. It is unlikely that such regional trends would be significantly changed by inclusion of a few Romanized false Tai place names from our data source. In fact, adding the 158 excluded "administrative region type features" to the Muang points did not alter the overall spatial distribution pattern of Muang as shown in Figs. 2 and 5.

The results of this study (the first such to the best our knowledge) quantitatively establish the relationship between toponyms and terrain characteristics that is related to wet rice farming of the Tai people. 
The spatial distribution of the Tai place names examined here also reveal a macro-regional view of some historically significant linguistic and cultural practices encapsulated in naming places that are common in the Tai-speaking domain and influenced by their wet rice agriculture. This macro-regional pattern is consistent with previous understanding of the Tai's migration in searching for flat land to grow wet rice.

This case study demonstrated that GIS-based geovisualization techniques can enhance the view of geographic patterns of toponyms from the vantage of transnational spatial distribution of Tai toponyms in southern China and Southeast Asia. By analyzing the terrain characteristics for basins with high concentrations of Tai toponyms, we determined quantitatively that these characteristics are particularly amenable for Tai wet rice agriculture. This study also demonstrated that the hybrid geography of bridging both physical and human geographies advocated by Kwan (2004) has great potential in helping us advance our fundamental understanding of the dynamics underlying social and cultural changes, the intricate interplay between language, history, migration, agriculture, and physical environment that lie behind the spatial patterns of Tai toponyms we see today.

\section{Conclusion}

Historically, Tai-speaking people settled in many intermontane basins, called Muang, meaning "basin" in proto-Tai, to grow wet rice. At the same time, they were a riverine people by inclination and used rivers large and small as avenues of trade and cultural transmission. As early Tai communities grew and came into contact with other ethno-linguistic groups, new regional patterns and practices of naming prominent places emerged in place of or in addition to declaring a place to be a Muang. Chiang and Viang are such examples of place naming influenced by the (Sino-) Tibeto-Burman speaking rulers of the Nan Chao kingdom following the Mongol invasions.

This research uses GIS to map the spatial distribution of places whose names start with Muang, Chiang, and Viang, and analyzes their relationship with terrain characteristics derived from digital elevation model (DEM) data. These Tai toponym locations have higher values of the compound topographic index (CTI), indicating the part of the landscape more likely to be saturated with water, than other toponym locations. Results also indicate that watershed basins with high concentrations of Muang (and its variants such as Muong, Meng, Meung, Mueng) are characterized by lower elevations, gentler slopes, and near zero Bolstad index (a measure of convexity and concavity with the value zero indicating a flat surface) values. All of these are consistent with physical conditions favorable for wet rice agriculture, which has had a great influence on where the Tai-speaking peoples live and how they name those places.

The research also shows that the mean distance to the nearest river for Chiang points is shorter than that for Viang locations. This can be explained by the fact that the Chiangs served as trading centers along waterways that brought in rice and other goods from the hinterland. This pattern underscores the role rivers played as communication (spread of names and trade), and as major sources of water in the wet rice agriculture practices of the Tai. Since the function of a Viang/Wiang "citadel, palisade" was principally one of providing defense for a Chiang, as defense outposts, they were often land-based locations on trails and roads and thus farther away from the Chiangs and from the rivers. Many of the Viang disappeared over time and, like some of the Chiang that also vanished, their existence can only be verified by studying older texts and chronicles, a task to be taken up by interested historians and archaeologists following the leads we have provided in this research.

Acknowledgments This research is supported by the National Science Foundation Human and Social Dynamics (HSD) Program (Grant No. 0623108). Any opinions, findings, and conclusions or recommendations expressed in this paper are those of the authors and do not necessarily reflect the views of the National Science Foundation. We also would like to thank two anonymous reviewers for their helpful reviews.

\section{References}

Barlow, J. (2005). The Zhuang: A longitudinal study of their history and their culture. http://mcel.pacificu.edu/as/ resources/zhuang/index.html. Accessed 18 May 2009.

Beven, K. J., \& Kirkby, M. J. (1979). A physically based, variable contributing area model of basin hydrology. Hydrological Sciences Bulletin, 24(1), 43-69.

Blackmore, M. (1960). The rise of Nan Chao in Yunnan. Journal of Southeast Asian History, 1(2), 47-61. 
Bolstad, P. V., Swank, W., \& Vose, J. (1998). Predicting southern appalachian overstory vegetation with digital terrain data. Landscape Ecology, 13(5), 271-283. doi: 10.1023/A:1008060508762.

Cohen, S., \& Kliot, N. (1992). Place-names in Israel's ideological struggle over the administered territories. Annals of the Association of American Geographers, 82(4), 653680. doi:10.1111/j.1467-8306.1992.tb01722.x.

Dai, H. (2004). On Xishuangbanna's Dai Toponyms, Doctoral dissertation, Central University of Nationalities, Beijing, China (in Chinese).

Diller, A. V. N., \& Edmondson, J. (Eds.). (2005). The Tai-Kadai Languages. London: RoutledgeCurzon.

Enfield, N. J. (2003). Linguistic epidemiology: Semantics and grammar of language contact in mainland Southeast Asia. London: Routledge Curzon.

Falvey, L. (2000). Thai agriculture: Golden cradle of millennia. Bangkok: Kasetsart University Press.

Gelling, M. (1988). Signposts to the past: Place-names and the history of England. Chichester: Phillimore.

Hartmann, J. F. (1998). A linguistic geography and history of Tai Meuang-Fai (Ditch-Dike) techno-culture. Journal of Language and Linguistics, 16(2), 68-100.

Hartmann, J. F. (2007). The power to name places: Ban, Muang, Chiang, Viang, Nakon, Krung. In J. Harris \& S. Burusphat (Eds.), Studies in Tai and Southeast Asian linguistics (pp. 139-154). Bangkok: Ekphimthai.

Hoang, L. (2004). Chiang and Wiang in the traditional social organization of the Tai. Tai Culture, 17, 48-55.

Horsman, S. (2006). The politics of toponyms in the Pamir mountains. Area, 38(3), 279-291. doi:10.1111/j.14754762.2006.00697.x.

Jett, S. C. (1997). Place-naming, environment, and perception among the Canyon de Chelly Navajo of Arizona. The Professional Geographer, 49(4), 481-493. doi:10.1111/ 0033-0124.00094.

Jiang, G. (1990). The use of place names in the study of China's physical environment. Chinese Geography and Environment, 3(3), 75-81. Translated from original in Chinese in Diming Congkan, 6, 1988.

Kashif, A.I. (2001). Africanisms Upon the Land: A Study of African Influenced Place Names of the USA: Proceedings of "Places of Cultural Memory: African Reflections on the American Landscape" conference in Atlanta, May 9-12, 2001. (http://www.nps.gov/history/crdi/conferences/AFR_ 15-34_Kashif.pdf).
Kato, K. (1998). Water irrigation and administration of the Tai of Sishuangpanna. Tai Culture, 3(2), 49-70.

Kaups, M. (1966). Finnish place names in Minnesota: A study in cultural transfer. Geographical Review, 56(3), 377397. doi: $10.2307 / 212463$.

Kwan, M.-P. (2004). Beyond difference: From canonical geography to hybrid geographies. Annals of the Association of American Geographers, 94(4), 756-763.

Luo, Y. (1996). The subgroup structure of the Tai languages: A historical-comparative study. Ph.D. dissertation. Australian National University.

Luo, W., \& Wang, F. (2003). Measures of spatial accessibility to healthcare in a GIS environment: Synthesis and a case study in Chicago region. Environment and Planning. B, Planning \& Design, 30(6), 865-884. doi:10.1068/b29120.

McDavid, R. I. (1958). Linguistic geographic and toponymic research. Names, 6, 65-73.

Miller, E. J. W. (1969). The naming of the land in the Arkansas Ozarks: A study in culture processes. Annals of the Association of American Geographers, 59(2), 240-251. doi:10.1111/j.1467-8306.1969.tb00668.x.

Moore, I. D., Grayson, R. B., \& Ladson, A. R. (1991). Digital terrain modeling: A review of hydrological, geomorphological, and biological applications. Hydrological Processes, 5(1), 3-30. doi:10.1002/hyp.3360050103.

Myers, G. A. (1996). Naming and placing the other: Power and the urban landscape in Zanzibar. Tijdschrift voor Economische en Sociale Geografie, 87(3), 237-246. doi: 10.1111/j.1467-9663.1998.tb01553.x.

Rhoads, B. L. (2004). Whither physical geography? Annals of the Association of American Geographers, 94(4), 748-755.

Rickard, L. S. (1968). Historic place names of New Zealand. Auckland: Minerva Books.

Wang, F. (2006). Quantitative methods and applications in GIS. Boca Raton, FL: CRC Press.

West, R. C. (1954). The term "Bayou" in the United States: A study in the geography of place names. Annals of the Association of American Geographers, 44(1), 63-74.

Wolock, D. M., \& McCabe, G. J. (1995). Comparison of single and multiple flow-direction algorithms for computing topographic parameters in TOPMODEL. Water Resources Research, 31(5), 1315-1324. doi:10.1029/95WR00471.

Wyatt, D. K. (1984). Thailand: A short history. Chiang Mai: Silkworm Books. 